\title{
Studentischer Arbeitseinsatz im Lippepark in Panschwitz-Kuckau
}

\author{
Clemens Böhmak
}

I

m Rahmen einer Lehrveranstaltung des Lehrgebietes Geschichte der Landschaftsarchitektur und Gartendenkmalpflege fand am 28. Oktober 2015 im Lippepark in Panschwitz-Kuckau ein Arbeitseinsatz mit Studierenden des 5. Semesters statt. Die Veranstaltung wurde finanziell von der Herbert-Heise-Stiftung für Gartenkunst und Landschaftskultur unterstützt.

Grundlage des Einsatzes war die Diplomarbeit des Autors mit dem Titel "Gartendenkmalpflegerische Erhaltungs- und Entwicklungskonzeption Lippepark - Lipjo«, die im Sommersemester 2015 am Lehrgebiet verfasst wurde. Ein Teil der dort vorgeschlagenen Pflegemaßnahmen sollte im Rahmen dieses eintägigen Parkseminars umgesetzt werden, wozu diese im Vorfeld mit den Denkmal- und Naturschutzbehörden vor Ort besprochen und festgelegt wurden.

Arbeitsschwerpunkt waren die klosternahen Parkbereiche zwischen Fischhälter und dem sogenannten Runden Teich. In diesem Zusammenhang befreite eine der Pflegegruppen einen Teilabschnitt des sogenannten Schönen Weges von den Fischhältern bis zum Ćišinskidenkmal von Spitz-Ahornsämlingen. Auch im Bereich des Denkmals selbst fanden Pflegearbeiten statt, wofür im Vorfeld des Arbeitseinsatzes hinter dem Ćišinkidenkmal zwei große Bäume - eine Rotbuche und ein Spitzahorn - entfernt wurden, welche die benachbarten Alteichen zunehmend bedrängten. Ein starker Rückschnitt der Eiben macht das Denkmal wieder von Weitem sichtbar und erlebbar.

Die zweite Gruppe hatte die Aufgabe, den Blick vom Runden Teich in Richtung Kloster in Teilen wieder freizustellen, so dass
Blickbeziehungen zwischen den Klostergebäuden und dem Park ermöglicht werden. Hierzu wurden die Kronenansätze über der Wiese behutsam aufgeastet, so dass die Bereiche unter den Kronen wieder pflegbar werden und der hier aufgekommene Wildaufwuchs, der ebenfalls entfernt wurde, nicht wieder aufwachsen kann.

Neben den Studierenden beteiligte sich auch das Kloster mit Arbeitskräften, Werkzeugen und einer Mittagsverpflegung am Arbeitseinsatz. So wurden mit Hilfe eines Radladers große Pflanztröge entfernt, die im Bereich des landschaftlichen Parks störend waren. Parallel dazu wurde eine Blut-Hasel, die den Blick in die Tiefe des Parks verstellte, gerodet und eine Winter-Linde als Hochstamm nach historischem Vorbild am Originalstandort gepflanzt (Abb. 1). Durch ihren hohen Kronenansatz ist jetzt wieder eine Blickbeziehung zwischen den Parkteilen möglich.

Der studentische Arbeitseinsatz soll als Initialzündung für zukünftige Einsätze fungieren. Im Sorbischen Rundfunk und in der Sorbischen Zeitung "Serbske Nowiny" wurde darüber berichtet. Mit Hilfe dieser Medien soll auch in Zukunft auf die Arbeitsätze aufmerksam gemacht werden. Es sind darüber hinaus weitere öffentlichkeitswirksame Maßnahmen, wie ein Frühlingsspaziergang im Jahr 2016, geplant. Ziel ist es, den Lippepark und seine gartenkünstlerischen Qualitäten verstärkt im Bewusstsein der Bevölkerung zu verankern und ihn durch gartendenkmalpflegerische Pflegeund Entwicklungsmaßnahmen für nachkommende Generationen zu erhalten. 




1 | Letzte Korrekturen an der Krone vor dem Einpflanzen der Winter-Linde. (Fotografie, Nora Kindermann, 2015).

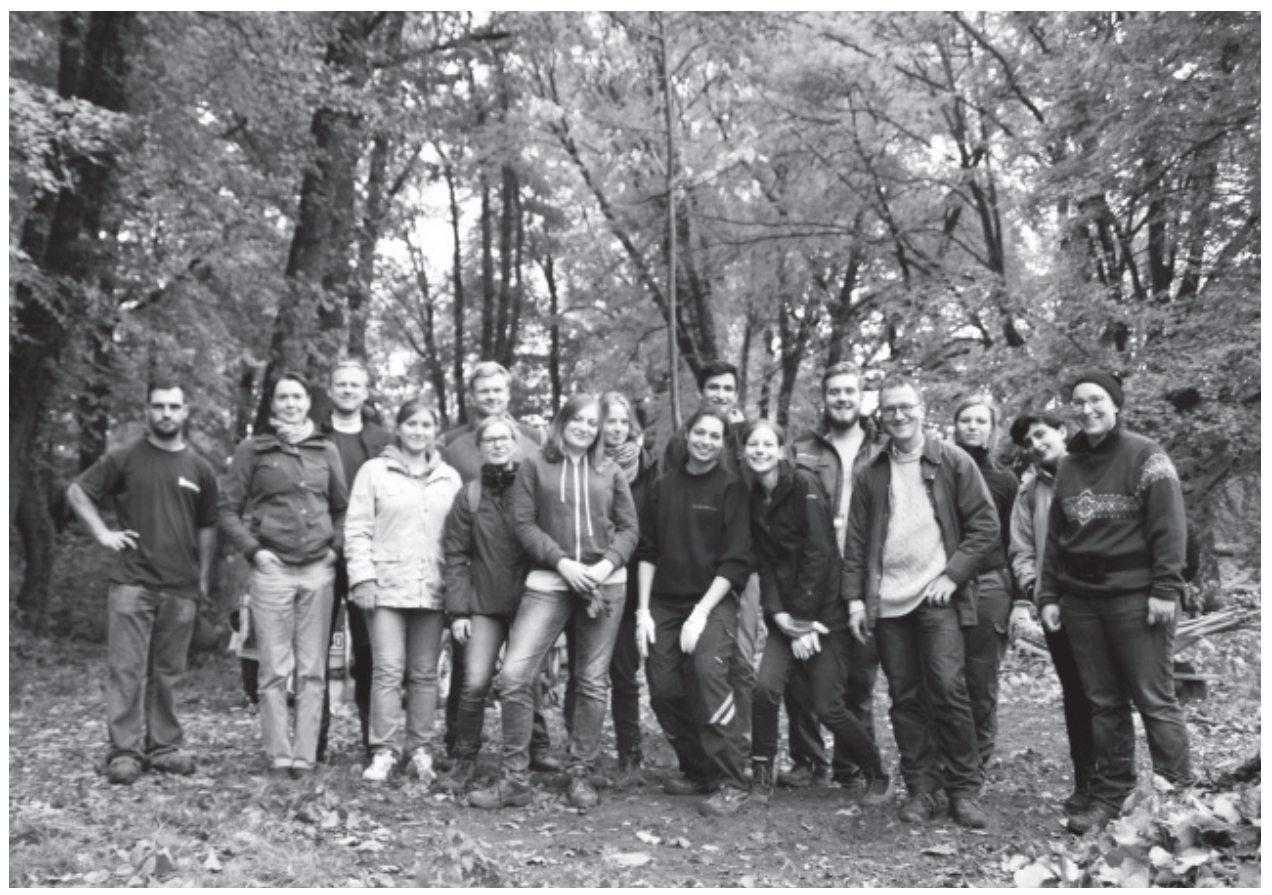

2 | Gruppenfoto nach erfolgreichem Abschluss der Pflegearbeiten. (Fotografie, Nora Kindermann, 2015). 